\title{
A comprehensive conceptual and bibliometric study of person-centered methodologies
}

\author{
Andrea Rey-Martí ${ }^{1}$ Pau Sendra-Pons ${ }^{2}$ (D) - Dolores Garzón ${ }^{3}$ - Alicia Mas-Tur ${ }^{3}$
}

Accepted: 15 December 2021 / Published online: 30 December 2021

(c) The Author(s) 2021

\begin{abstract}
Person-centered approaches, such as latent profile analysis (LPA) and qualitative comparative analysis (QCA), have gained in popularity in organizational scholarship because of their ability to provide insight into how interrelations between a group of conditions can lead to a particular outcome. Despite the growing acceptance of person-centered approaches in social science research, traditional variable-centered approaches continue to prevail, although their dominance is increasingly questioned. This paper offers in-depth analysis of the current state of QCA and LPA from both a conceptual and a bibliometric perspective. This study thus aims to contextualize the role of person-centered methodologies in organizational scholarship. This aim is important, given the significance of exploring novel approaches to advance knowledge in organizational research. This paper provides scholars with quantifiable and readily comparable information on the use of these emerging but promising methods in organizational studies. Ultimately, this scientific contribution sheds light on the current and prospective applications of person-centered methods in research. Moreover, it offers scholars who are considering applying these methods objective analysis of the scientific production in this area thus far.
\end{abstract}

Keywords Qualitative comparative analysis (QCA) · Latent profile analysis (LPA) · Person-centered approaches $\cdot$ Bibliometrics

\section{Introduction}

Scholars use both variable-centered and person-centered approaches in scientific research. The former are based on the assumption of population homogeneity, and they have low specificity because they do not describe subjects precisely. In contrast, person-centered approaches have a higher degree of specificity, describing subpopulations within a sample separately rather than as part of the general sample. In terms of parsimony, however,

Pau Sendra-Pons

pau.sendra-pons@uv.es

$1 \quad$ ESIC Business \& Marketing School, Valencia, Spain

2 Department of Corporate Finance, Faculty of Economics, Universitat de València, Valencia, Spain

3 Department of Business Administration, Faculty of Economics, Universitat de València, Valencia, Spain 
variable-centered approaches are often easier to interpret person-centered approaches, whose level of detail when specifically describing different subpopulations increases complexity (Howard and Hoffman 2018).

A notable person-centered approach is latent profile analysis (LPA). LPA is a latent variable modeling technique in which the unobserved heterogeneity within a sample is acknowledged. Therefore, different constellations of constructs can be identified, unlike in variable-centered approaches, which disregard such nuances (Morin et al. 2011; Gabriel et al. 2018). Another person-centered approach, qualitative comparative analysis (QCA), arises when quantitative methods meet qualitative methods (Ragin 1987; 2000). QCA aims at determining causality using systematic comparisons (Mill 1843; Roig-Tierno 2017).

The current study is aimed at providing both a conceptual and a bibliometric approach to the person-centered approaches of QCA and LPA. The motivation behind this research is to contextualize this area of study further while describing the future research prospects in terms of hot topics. The relevance of the study lies in providing objective and quantifiable information on the intricacies of these methods to inform prospective researchers about applications and scientific production in relation to these methods. The study also makes a relevant contribution to the future research agenda.

Conceptually, the article provides a theoretical framework to contextualize these two person-centered approaches, highlighting their specific features when used in scientific research. This theoretical framework also serves as a starting point for the bibliometric analysis that is presented later in the article. The quantitative and qualitative insight provided by this bibliometric analysis gives readers an objective overview of this research topic that can help the academic community plan the research agenda for the coming years.

The article is organized as follows. First, a theoretical background is provided in relation to QCA and LPA. Second, the method employed in the bibliometric study is described. Third, the results of the bibliometric analysis are discussed. Finally, the conclusions are presented.

\section{Theoretical background of person-centered approaches}

Person-centered approaches, unlike variable-centered approaches, describe the differences between individuals in terms of how variables relate to each other. That is, person-centered approaches are concerned with "the identification of groups of individuals who function in a similar way at the organism level under investigation and in a different way relative to other individuals at the same level" (Magnusson 2003, p. 16). Thus, these methodologies identify groups or classes of individuals who share attributes or relationships between attributes, as in the case of QCA (Laursen and Hoff 2006).

There are three characteristic features of person-centered analyses. First, they consider that the population is heterogeneous. Therefore, variables are believed to influence the population in different ways and not in the homogeneous manner that is assumed in variablecentered analyses. Second, patterns of association within and between groups are sought. Third, the stability of cases is determined through the identification of categories of individuals at multiple points in time (Laursen and Hoff 2006). Thus, patterns are detected between variables that differ from those for other categories of individuals in terms of the relationships between the variables, and group membership is identified (Laursen and Hoff 2006), as occurs in QCA. 
Person-centered analysis is sometimes not statistically accepted because some scholars believe that the existence of methods that capture individual differences in developmental patterns make person-oriented analyses unnecessary. Another erroneous belief relates to the interpretation of the results to create groups and determine group membership. Nonetheless, person-centered methods are increasingly used. Finally, some academics see person-centered analyses as qualitative instead of quantitative because they deal with cases and not variables. However, this view might not be valid because empirical analyses are employed to identify meaningful natural groupings that share similar salient properties (Bergman et al. 2003; Laursen and Hoff 2006). As explained by Laursen and Hoff (2006, p. 381), "Person-centered analyses are designed to identify qualitatively different groups of individuals based on the clustering of multiple variables, but the measurement of these variables and the derivation of groups or categories of individuals is absolutely quantitative." QCA's use of both quantitative and qualitative data is a core characteristic of this method.

\subsection{Qualitative comparative analysis (QCA)}

QCA is a person-centered approach because it is based on configurational analysis that enables comparisons between cases, offers a detailed understanding of each case, and reveals both the combinations of conditions related to a given outcome and the groups of subjects associated with those combinations (Ragin 2000, 2008). QCA reveals the combinations of minimally necessary and/or sufficient conditions that lead to a certain outcome (Ragin 2008). It works from a complex causality perspective and assumes asymmetric relationship between the observations. Equifinality can be identified in configurational approaches, which are addressed as different types of cases whereby the same outcome can be reached from different paths (Katz and Kahn, 1978). In QCA, calibration is performed using fuzzy-set logic, thus combining qualitative and quantitative methods (Vink and Vliet 2009; Vis 2012, Baumgartner 2021). The result is several combinations which, in terms of this methodology, should be called configurations (Longest and Vaisey 2008). Therefore, QCA is a suitable method for researchers who seek the juxtaposition of two types of analysis: case-oriented and variable-oriented (De Meur and Rihoux 2002).

Configurations are combinations of variables or factors, which in QCA terminology are referred to as conditions. These structural configurations are minimally necessary or sufficient for an outcome of interest to occur (Meyer, Tsui, and Hinings 1993). Necessary conditions are always present when the outcome occurs. In contrast, conditions are sufficient for an outcome if that outcome occurs whenever the condition is present (Ragin 2008; Schneider and Wagemann 2012). However, the outcome can occur in the presence of other conditions (Woodside 2013).

This method has the advantage of being statistically valid for small samples. It is possible to conduct studies with samples of 10 to 50 cases, making this method highly attractive for social science research (Fiss 2007). According to Vassinen (2012), this validity with small samples is thanks to three aspects. First, under the holistic approach, data are viewed as integral sets whose components are related to each other such that variables are seen not as independent values but as combinations. Second, the configurational perspective of causality implies, as mentioned earlier, the same outcome can be reached through different configurational patterns (equifinality), allowing the interaction of the conditions in causally heterogeneous and contextually idiosyncratic ways. Third, the method uses qualitative interpretations to calibrate fuzzy-set membership 
scores. This is followed by the construction of a causal discourse around the results of the analysis through which the relationships present in the configurational patterns are articulated.

The steps defined by Ragin (2009) in order to perform QCA are now presented. First, the conditions must be calibrated. The degree of membership of each condition must be calibrated using ordinal or interval scales in terms of degrees of set membership (Wu, Yeh, Huan, and Woodside 2014). At this point, the researcher's knowledge is crucial (Fiss 2007; Woodside 2013). The researcher must establish when a case has full set membership by assigning a membership score of 1.00 , full set non-membership by assigning a score of 0.00 , and ambiguity in terms of set membership (i.e., the crossover point when a case is neither inside nor outside the set) by assigning a score of 0.5 (Ragin 2000, 2008). Next, necessity analysis is performed. This analysis determines whether a condition is necessary for the outcome to occur. According to Schneider and Wagemann (2012), a necessary condition must have a consistency value greater than 0.9 .

In the next step, the truth table is constructed. This table is a data matrix with $2^{\mathrm{k}}$ rows, where $\mathrm{k}$ is the number of causal conditions used in the analysis and the rows correspond to each of the possible empirical outcomes (Fiss 2011; Schneider and Wagemann 2012). This table shows all possible structural configurations (Fiss 2011). In this table, scores determine which cases are assigned to which combinations, i.e. cases with a score higher than 0.7 are assigned to the corresponding combination. Subsequently, the different structural configurations or combinations of conditions that lead to an outcome are identified using Boolean logic. At this stage, two parameters must be considered: coverage and consistency. Coverage indicates to which extent a solution is empirically relevant (the higher the better). That is, coverage refers to the number of cases for which a configuration is valid (RoigTierno et al. 2017). However, a configuration with low coverage is not necessarily less relevant because configurations with low coverage are sometimes useful to explain a set that causes a particular outcome (Ragin 1987, 2000; Woodside and Zhang, 2012; Roig-Tierno et al. 2017). Consistency quantifies the degree to which cases sharing similar conditions are associated with the same outcome (Roig-Tierno et al. 2017). Following the recommendation of Ragin (2008), a minimum consistency of 0.8 is sufficient to indicate goodness of fit. Finally, combinations are simplified by the algorithm while Boolean algebra is used to minimize the table and maximize the number of comparisons, and identify causal inferences, revealing the conditions that are minimally sufficient to achieve the outcome (Crawford 2012). Occasionally, before the three solutions appear, the program may prompt the researcher to clarify the prime implicants, which emerge as a result of Boolean minimization in the form of reduced expressions (Ragin, 2006a). In this part of the process, the role of the researcher is crucial when it comes to determining which conditions are present or absent.

Finally, three solutions are given: (1) the complex solution, which includes neither easy nor difficult counterfactuals, (2) the parsimonious solution, which includes all simplifying assumptions with the help of decisions made by the researcher, and (3) the intermediate solution, which includes simplifying assumptions based on easy counterfactuals (Ragin, 2008). The researcher must choose which solution should be used to interpret the configurations identified during the analysis.

QCA has been used in research in diverse areas such as management (Greckhamer et al. 2008; Fiss 2011; Sendra-Pons et al. 2021), civil engineering (Forsythe 2012), social psychology (Yong 2020), computer information systems (Rivard and Lapointe 2012), library science (Cabrilo and Dahms 2018), and industrial labor relations (Allen and Aldred 2011). 


\subsection{Latent profile analysis (LPA)}

As explained earlier, LPA is a latent variable modeling technique that recognizes unobserved heterogeneity within a sample, allowing various constellations of constructs to be identified. It thus differs from variable-centered approaches that ignore these complexities (Morin et al. 2011; Gabriel et al. 2018). LPA is particularly suitable when a large number of continuous variables must be recoded into different subgroups (Oberski 2016). It is similar to latent class analysis (LCA) because both techniques are used to delve deeper into hidden psychological aspects to characterize different profiles more effectively. The main attraction of LCA is that it makes it possible to divide and classify the data in such a way as to explain a heterogeneous group in terms of several homogeneous groups. In short, both person-centered mixture modeling analyses are able to identify subgroups in a categorical latent variable (Williams and Kibowski 2016).

Oberski (2016) explicitly and intuitively defined mixture modeling, to which LPA is ascribed, as "the art of unscrambling eggs." This metaphor alludes to the fact that, as explained earlier, LPA recovers hidden groups from the observed data, initially characterizing how those groups should be, and then gives the probability that each person belongs to those groups by looking at the distributions within such groups. Mixture modeling differs from other types of latent variable modeling in that it uses discrete latent variables (i.e., different categories of an unobserved nominal or ordinal variable). However, even though LPA and LCA are similar in essence, they differ in some ways. In LCA, the assumption of local independence applies. According to Vermut and Magidson (2004) this assumption means that "the observed items are independent of each other given an individual's score on the latent variable(s)." Moreover the different posterior probabilities of embracing each indicator variable based on class membership characterize the latent classes. In contrast, local independence does not apply in LPA, while the different mean scores on each indicator variable, conditioned to class membership, illustrate the most appropriate LPA solution (Williams and Kibowski 2016).

LPA has been used in research in diverse areas such as tourism (Morosan and DeFranco 2019), housing policy (Charles 2020), education (Bergold et al. 2017; Pedaste and Must 2018; Hodis and Hodis 2020), behavior (Chen et al. 2019; Gong et al. 2020), sports science (Haraldsen et al. 2020), health (Koko and Feldt 2018; Horacek et al. 2019; Park et al. 2019), culture (Grigoryev and van de Vijver 2017), and sustainability (Hine et al. 2016).

\section{Method}

Bibliometric analysis of both QCA research and the LPA literature was conducted. This type of analysis allows to evaluate scientific activity by providing objective information to interested parties (Duque Oliva et al. 2006; Rey-Martí et al. 2016). It consists of using statistical methods to analyze the qualitative and quantitative changes that have arisen in a research topic (De Bakker, Groenewegen, and DenHond, 2005).

For this purpose, data were gathered from the Web of Science (WOS), which provides a database of papers published in indexed journals. Additionally, graphical representations of the results were produced using VOSviewer 1.6.15. software. These representations depict the connections between scientific publications, scientific journals, researchers, research 
organizations, countries, and keywords (Mas-Tur et al. 2019). The analysis was carried out in May 2021, by searching the WOS Core Collection. First, the "subject" field was searched using the term "qualitative comparative analysis". The search thus looked in the database for these three words together in the title, abstract, and keywords of the documents included in the database. The term "QCA" was initially included in the search. However, it was removed because this acronym refers to "quantum cellular automata" in medicine. Therefore, the inclusion of this term might have distorted the results of the search. The search found 2426 documents. As is common in bibliometric analysis, the search was restricted to articles, reviews, notes, and letters, resulting in 2268 articles and reviews because there were neither notes nor letters among the search results (Merigo et al. 2015; Merigó et al. 2016; Cancino et al. 2017; López-Rubio et al. 2020; Mas-Tur et al. 2021). The term "paper" rather than "article" is used in the remainder of the analysis to refer to any of these forms of research output.

Second, a search in the WOS Core Collection was performed using the "subject" search field and the search term "latent profile analysis". Again, the search looked in the database for the three words together in the title, abstract, and keywords of the documents included in the database. As with the term "QCA", the term "LPA" was also removed because this acronym refers to "lysophosphatidic acid" in cell biology. The search found 2239 documents corresponding to the aforementioned types of research output. However, the number of papers included in the bibliometric analysis amounted to 2150 documents. In this case, no notes were found.

\section{Results}

\subsection{Qualitative comparative analysis (QCA)}

The bibliometric indicators used in this research were (1) areas of knowledge where authors have published research on QCA, (2) evolution of the publication of QCA research documents, (3) authors who have published research on QCA, (4) journals that have published research on QCA, and (5) most cited articles on QCA.

\subsubsection{Areas of knowledge where authors have published research on QCA}

There are 103 areas in which scholars have published research on QCA. Figure 1 shows the 10 research areas where the most papers on QCA have been published. The area where the most papers have been published is Business Economics, with 925 published documents, followed by Government Law, with 311 documents, and Environmental Sciences Ecology, with 215 documents. The areas with the lowest number of publications are Psychology, with 83 documents, Engineering, with 75 documents, and Public Environmental Occupational Health, with 69 documents.

\subsubsection{Evolution of the publication of QCA research documents}

Figure 2 shows that the first time a document mentioning "qualitative comparative analysis" appeared was in 1977. After that, nothing was published until 1984. There was then another jump until 1991. After that year, "qualitative comparative analysis" became a more common research topic, with papers published every year except 1993. The number of 


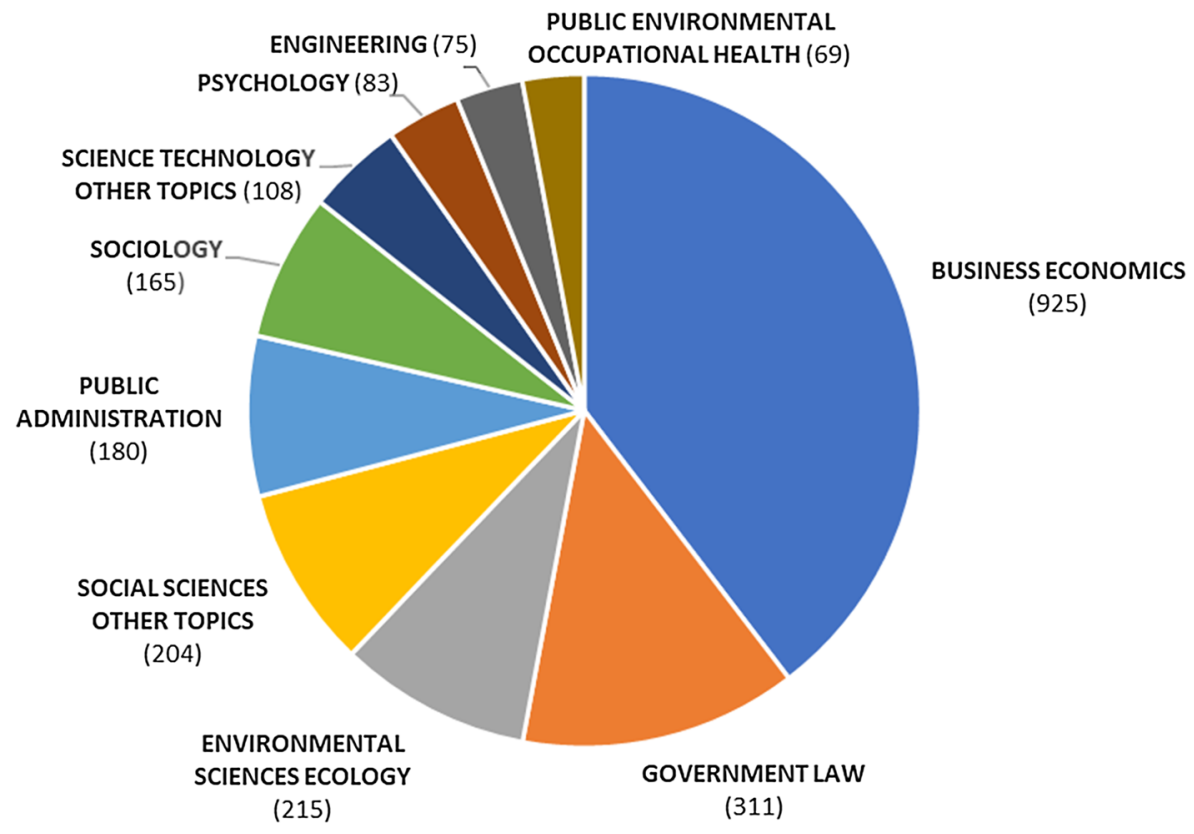

Fig. 1 Areas of knowledge where research on QCA has been published

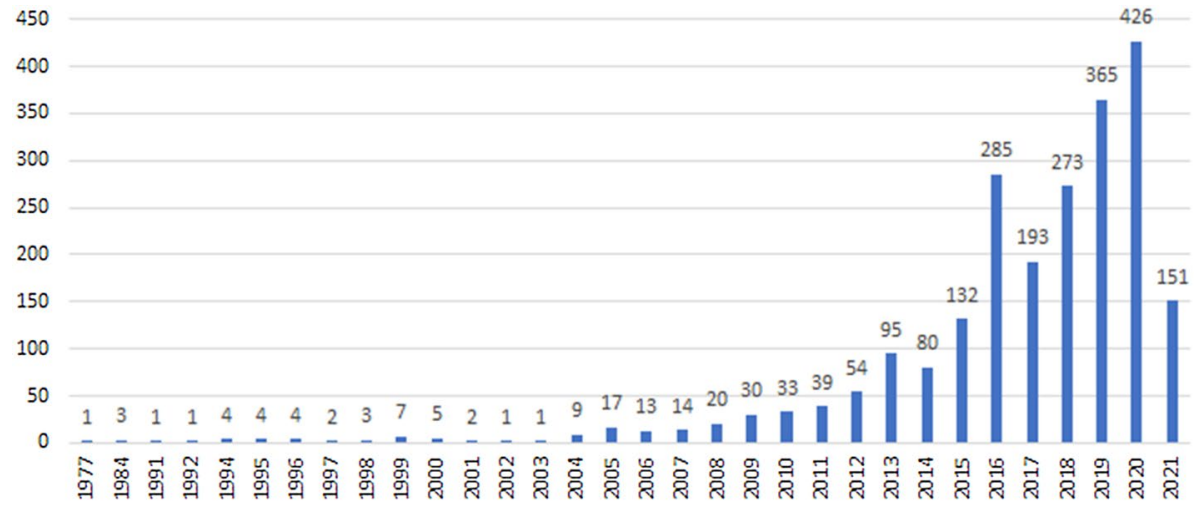

Fig. 2 Evolution of the number of published papers on QCA (1977-2021)

publications has grown year on year. In 2016, there was a large increase in publications, from 132 to 2015 to 285 in 2016. Similar numbers have since been maintained. As of May 2021, 151 documents on QCA have been published in 2021.

This methodology was developed in 1943 by J. Mill. The first publication on QCA, authored by Holly Skodol Wilson in 1977, is "Limiting Intrusion-Social Control of Outsiders in a Healing Community". It was published in the journal Nursing Research in the field of nursing. Analysis of this article shows that, according to the author, the method of "comparative analysis" was used. The author defined this method as "a general 
sociologic-anthropologic method of research involving the systematic choice and study of several comparison groups which can be social units of any size" (Wilson 1977, p. 106).

As explained earlier, QCA as we know it today was developed by C. Ragin in 1987. Therefore, analysis was performed to examine the first paper published after that date. It was not until 1991 that the article "Theoretical generality, case particularity: Qualitative comparative analysis of trade union growth and decline" by Griffin Botsko was published in the International Journal of Comparative Sociology. This article, in the area of sociology, uses QCA to show the patterns of trade union membership growth and decline in the 18 largest and most politically stable capitalist democracies in the 1970 and $1980 \mathrm{~s}$.

\subsubsection{Authors who have published research on QCA}

A total of 4,784 authors have published research on QCA. Table 1 shows the authors with the most publications on QCA. As in the other analyses, the first 10 results are analyzed. However, if two or more authors have the same number of publications, they appear in alphabetical order in WOS. Therefore, the 11 authors with the most publications are listed so as not to exclude any authors with the same number of publications as another. The author with the most publications on QCA is Arch G. Woodside, with 28 publications.

The number of citations that an article receives and the studies cited in an article are two of the most widely used bibliometric indicators to determine the quality of an article (Duque Oliva et al. 2006; Rey-Martí et al. 2016). Arch G. Woodside is the most cited author, with 1391 citations, followed by Carsten Q. Schneider, with 1028 citations, and Benoit Rihoux, with 512 citations. Regarding the average number of citations per year, Woodside again leads the ranking, with 139.10, followed by Carsten Q. Schneider, with 68.53 citations, and Sascha Kraus, with 61.67 citations. The h-index is also a relevant measure. An author/article/journal with an h-index of $x$ has $x$ articles with at least $x$ citations. Woodside has an h-index of 14, followed by Alrik Thiem (13), Sascha Kraus (11), and Stefan Verweij, Carsten Q. Schneider, and Judith Glaesser (10). Finally, Carsten Q. Schneider (64.25), followed by Arch G. Woodside (49.68) and Benoit Rihoux (42.67), has the highest average number of citations per paper.

Table 1 Most relevant authors in the field of QCA

\begin{tabular}{lrrrrl}
\hline Author & TP & \multicolumn{1}{c}{ TC } & TC/Y & h-index & TC/P \\
\hline Arch G. Woodside & 28 & 1391 & 139.10 & 14 & 49.68 \\
Alrik Thiem & 23 & 436 & 44.84 & 13 & 18.96 \\
Stefan Verweij & 20 & 246 & 27.33 & 10 & 12.3 \\
Norat Roig-Tierno & 16 & 305 & 50.83 & 8 & 19.06 \\
Carsten Q. Schneider & 16 & 1028 & 68.53 & 10 & 64.25 \\
Kun Huang Huarng & 15 & 220 & 31.43 & 8 & 14.67 \\
Sascha Kraus & 13 & 370 & 61.67 & 11 & 28.46 \\
Ingo Rohlfing & 13 & 292 & 22.46 & 8 & 22.46 \\
Judith Glaesser & 12 & 196 & 16.33 & 10 & 16.33 \\
David Pickernell & 12 & 87 & 14.50 & 4 & 7.25 \\
Benoit Rihoux & 12 & 512 & 34.13 & 9 & 42.67 \\
\hline
\end{tabular}

$\mathrm{TP}=$ total publications, $\mathrm{TC}=$ total citations, $\mathrm{TC} / \mathrm{Y}=$ total citations per year, $\mathrm{TC} / \mathrm{P}=$ total citations per paper 


\subsubsection{Journals that have published research on QCA}

In total, 978 journals have published research on QCA. Table 2 shows the 10 most relevant journals in terms of number of publications. The journal with the most publications and citations on QCA is the Journal of Business Research, with 277 publications and 6122 citations. Arch G. Woodside, the author with the most publications and citations, is a former Editor-in-Chief of this journal. Quality \& Quantity also appears in the ranking, with 25 published articles and 173 citations.

In terms of total citation ranking, the Journal of Business Research (6122) is followed by Sociological Methods Research (959) and Psychology \& Marketing (292). With respect to the average number of citations per year, the three journals that lead the ranking are Journal of Business Research (470.92), Psychology \& Marketing (36.50), and Sociological Methods Research (35.52), which are the same journals that lead the citations ranking but in a different order. The highest h-index corresponds to the Journal of Business Research (42), followed by Sociological Methods Research (15) and Industrial Marketing Management (10), with much smaller values. Lastly, the highest average number of citations per paper corresponds to Sociological Methods Research (33.07), the Journal of Business Research (22.1), and the Journal of European Public Policy, which, despite not being in the top three in terms of the total number of citations, has an average number of citations of 16.14 .

\subsubsection{Most cited articles on QCA}

Analysis of the five most cited papers on QCA was performed. Table 3 shows that the most cited paper on QCA is "Stress, coping, and social support processes: Where are we? What next?" by Thoits (1995), with 1442 citations. This paper uses QCA, optimal matching analysis and event structure analysis to help advance research in areas such as stress.

Arch G. Woodside again appears in the ranking, occupying the third position with 719 citations for his article "Moving beyond multiple regression analysis to algorithms: Calling for adoption of a paradigm shift from symmetric to asymmetric thinking in data analysis

Table 2 Most relevant journals by number of publications on QCA

\begin{tabular}{lrrrrr}
\hline Journal & TP & TC & TC/Y & h-index & TC/P \\
\hline Journal of Business Research & 277 & 6122 & 470.92 & 42 & 22.1 \\
Sustainability & 59 & 229 & 32.71 & 8 & 3.88 \\
Sociological Methods Research & 29 & 959 & 35.52 & 15 & 33.07 \\
Quality Quantity & 25 & 173 & 17.30 & 7 & 6.92 \\
Psychology Marketing & 19 & 292 & 36.50 & 9 & 15.37 \\
Industrial Marketing Management & 18 & 259 & 32.38 & 10 & 14.39 \\
Technological Forecasting and Social Change & 17 & 189 & 21.00 & 6 & 11.12 \\
Economic Research-Ekonomska Istraživanja & 16 & 34 & 11.33 & 3 & 2.13 \\
International Journal of Social Research Methodology & 15 & 151 & 11.62 & 7 & 10.07 \\
Journal of European Public Policy & 14 & 226 & 14.13 & 8 & 16.14 \\
\hline
\end{tabular}

$\mathrm{TP}=$ total publications, $\mathrm{TC}=$ total citations, $\mathrm{TC} / \mathrm{Y}=$ total citations per year, $\mathrm{TC} / \mathrm{P}=$ total citations per paper 


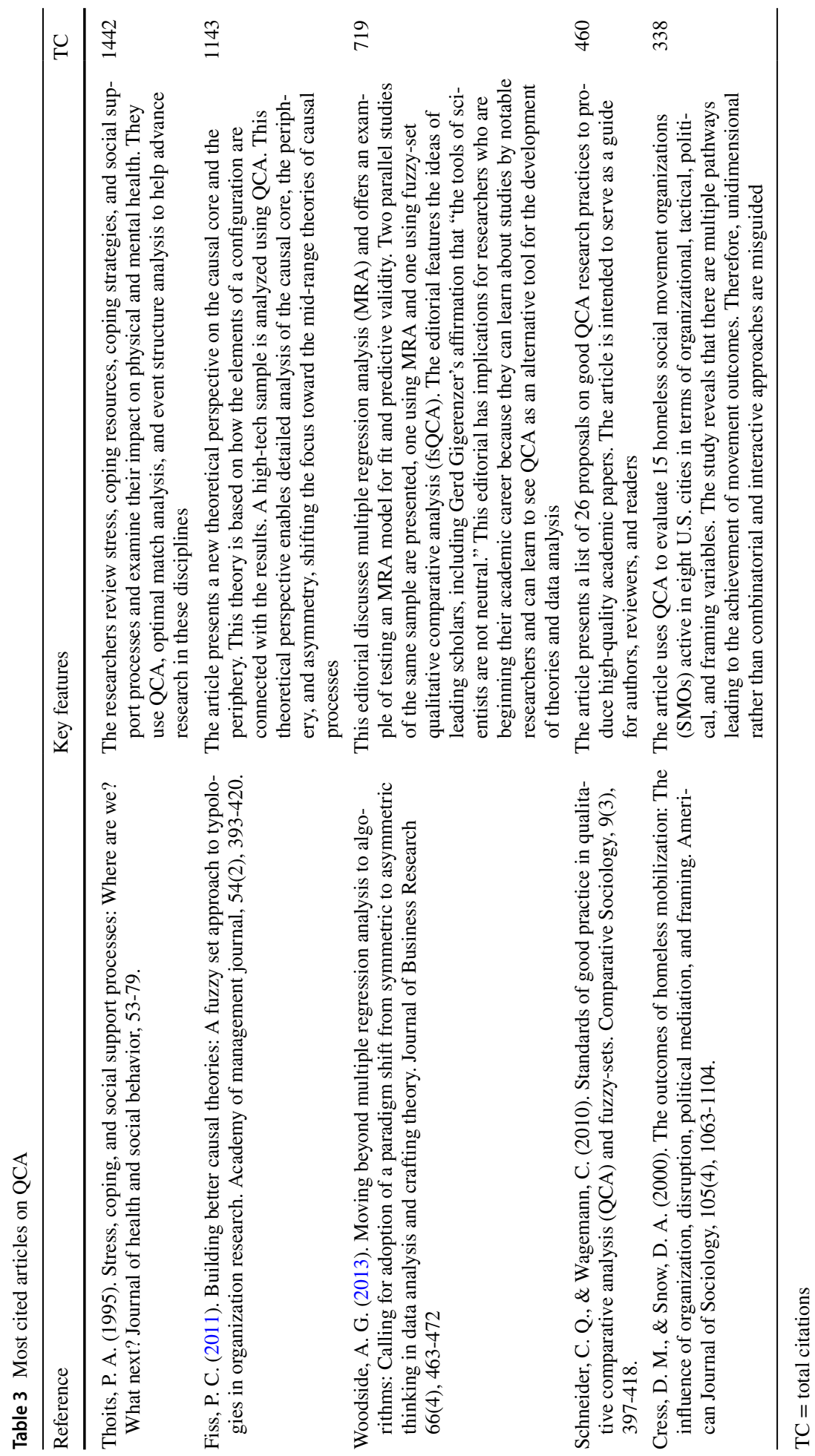


and crafting theory" published in 2013 in the Journal of Business Research. This finding confirms that Woodside is an experienced author on QCA.

Figure 3 shows the list of authors who have published together and the number of citations of these studies. To appear in this list, the minimum number of documents by each author was five. The figure shows a total of 117 authors forming 53 groups. Clusters are shown by colors rather than ties for clarity purposes. The density of ties would distort the analysis. Notable groups include those formed by Woodside, who is the author with the most publications and the most QCA citations. Another notable author in the figure is Fiss, who does not appear in the table of authors with the most publications but does appear in the table of the most cited authors.

\subsection{Latent profile analysis (LPA)}

The bibliometric indicators used for the LPA were (1) areas of knowledge where authors have published research on LPA, (2) evolution of the publication of LPA research documents, (3) authors who have published research on LPA, (4) journals that have published research on LPA, and (5) most cited articles on LPA.

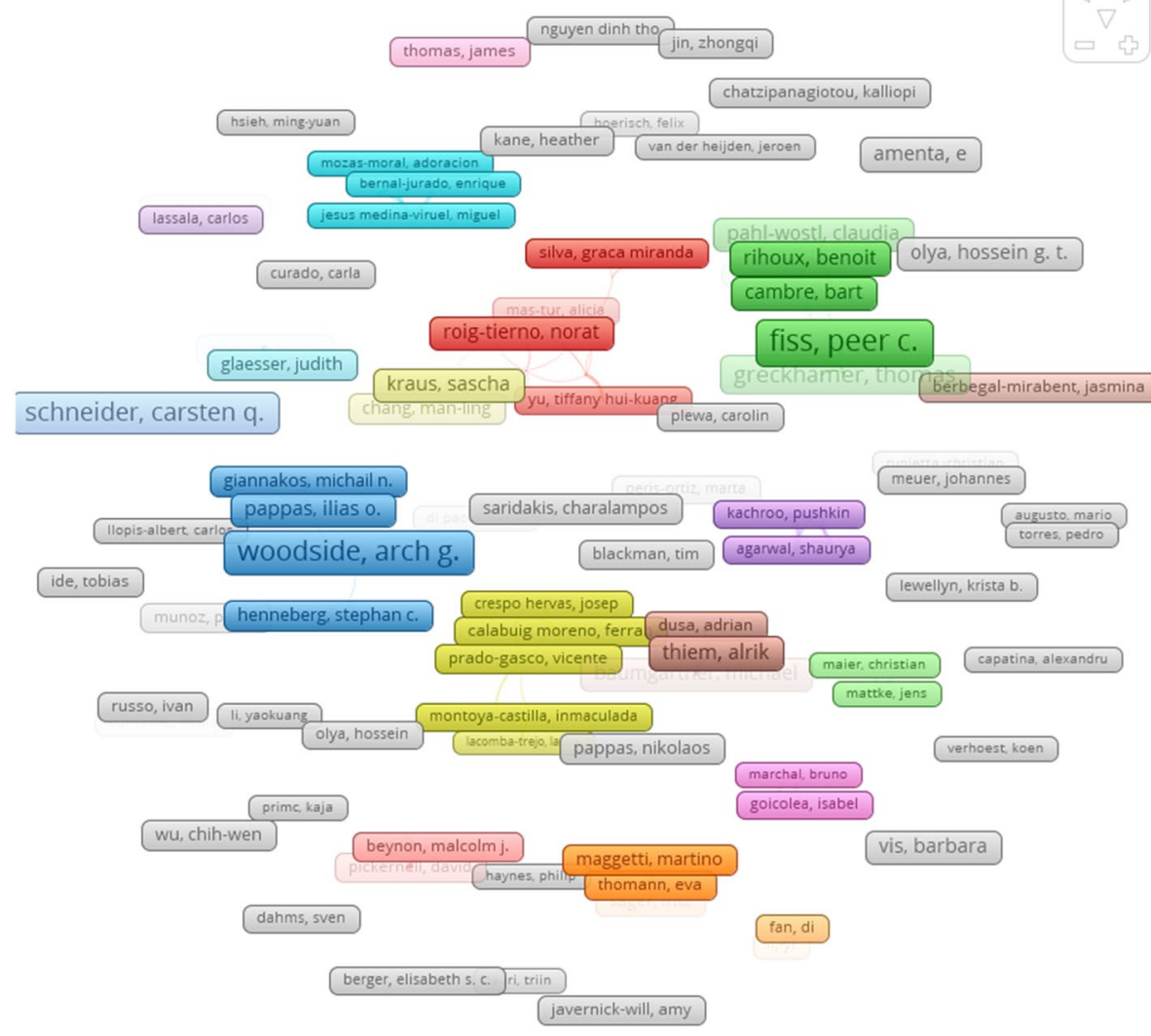

Fig. 3 Co-authorship of publications on QCA 


\subsubsection{Areas of knowledge where authors have published research on LPA}

LPA research has been published in 90 knowledge areas. Figure 4 shows the 10 research areas where the most papers have been published on LPA. Almost half of the graph is occupied by Psychology, with 1227 documents, followed by Psychiatry, with 327 documents, and Education - Educational Research, with 207 documents. The areas with the lowest scientific production are Substance Abuse, with 85 documents, Business Economics, with 75 documents, and Social Work, with 72 documents.

\subsubsection{Evolution of the publication of LPA research documents}

Figure 5 shows the evolution of the number of publications on LPA. Until 2014, the number of annual publications had not exceeded 100, and until 2005, at most one document was published per year. Although the trend in the number of publications is upward, in 2019 , there was a spike in the number of publications, which rose from 264 to 2018 to 377 in 2019. So far in 2021, 192 documents have been published.

\subsubsection{Authors who have published research on LPA}

In total, 7,234 authors have published research on LPA. Table 4 shows the 11 authors (using the same criteria as in the previous analysis) with the most publications on LPA. The author with the most publications on LPA is Ross D. Crosby, with 22 published papers and 921 citations of these papers. The author with the most citations is Alexandre J. S., with 988 citations from 20 publications.

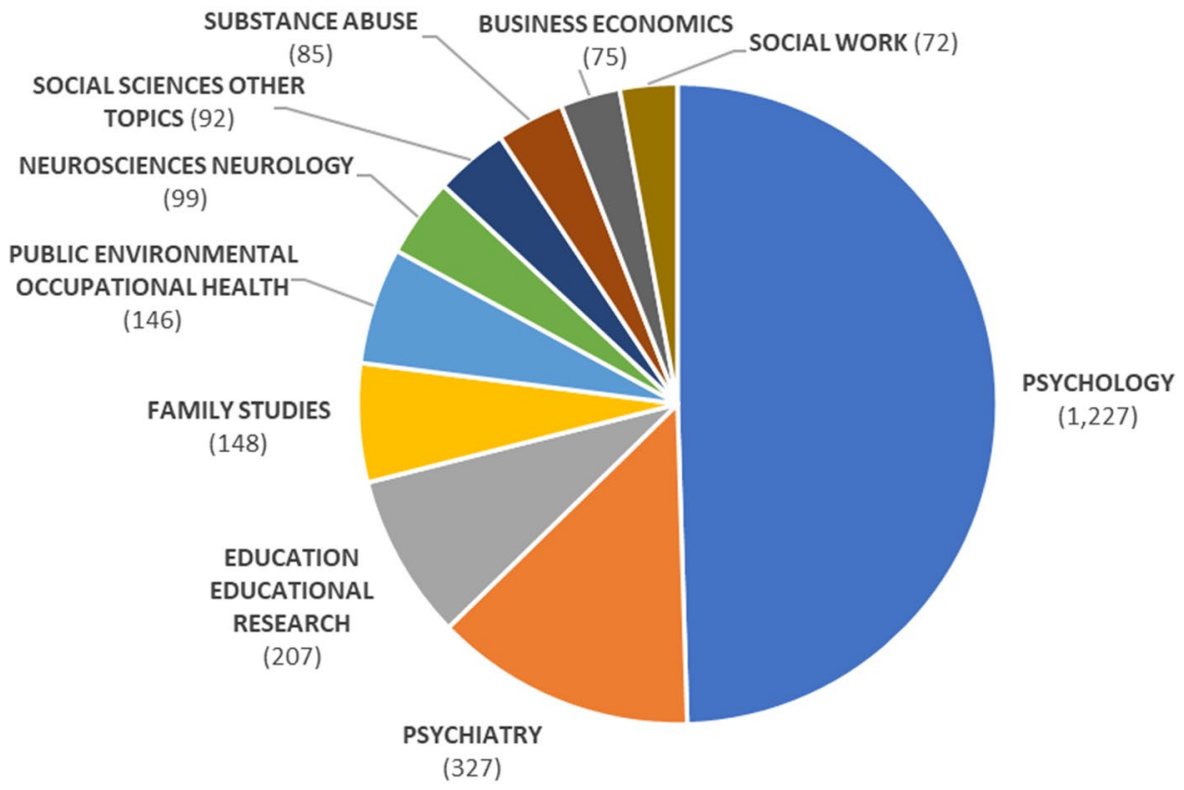

Fig. 4 Areas of knowledge where research on LPA has been published 


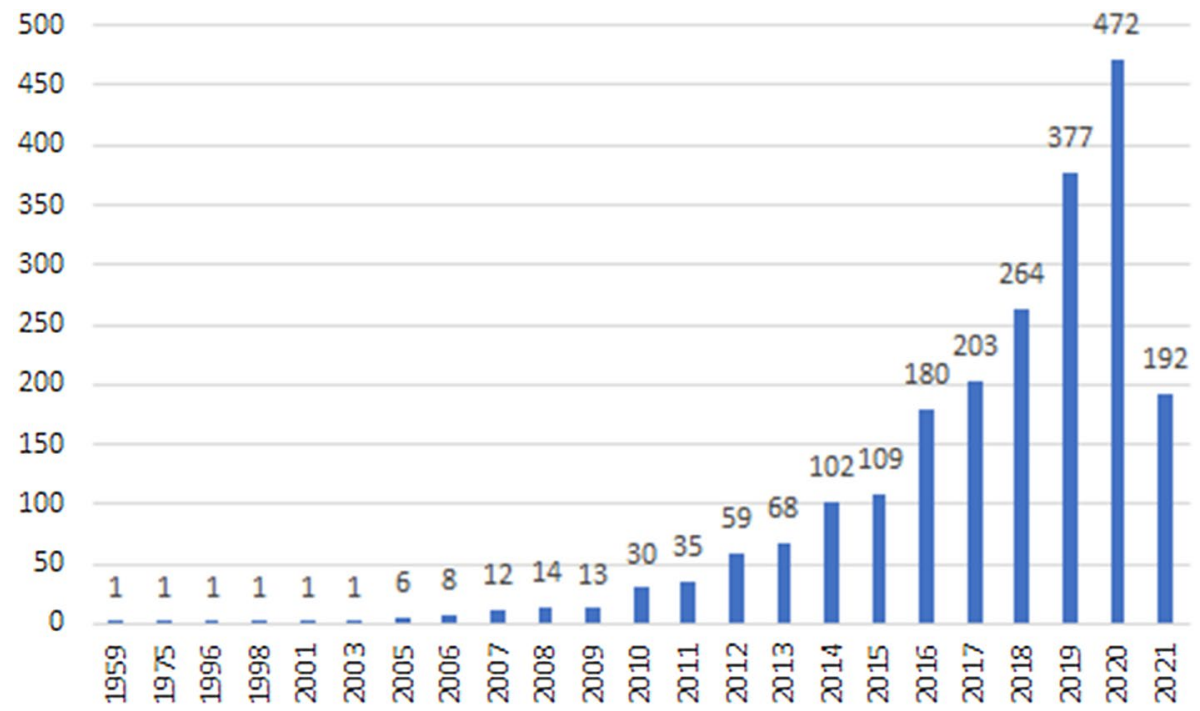

Fig. 5 Evolution of the number of documents published on LPA (1959-2021)

Table 4 Most relevant authors in the field of LPA

\begin{tabular}{lccccc}
\hline Authors & TP & TC & TC/Y & h-index & TC/P \\
\hline Ross D. Crosby & 22 & 921 & 57.56 & 15 & 41.86 \\
Alexandre J. S. Morin & 20 & 994 & 82.83 & 10 & 49.7 \\
Michael G. Vaughn & 19 & 461 & 32.93 & 12 & 24.26 \\
Chris G. Sibley & 18 & 188 & 23.50 & 8 & 10.44 \\
Stephen A. Wonderlich & 17 & 645 & 40.31 & 10 & 37.94 \\
Christine Miaskowski & 16 & 104 & 10.40 & 5 & 6.5 \\
Taru Feldt & 15 & 187 & 20.78 & 9 & 12.47 \\
Ulla Kinnunen & 15 & 257 & 28.56 & 9 & 17.13 \\
James E. Mitchell & 14 & 564 & 35.25 & 10 & 40.29 \\
Cherie Armour & 13 & 275 & 30.56 & 9 & 21.15 \\
Christopher P. Salas-Wright & 13 & 327 & 32.70 & 8 & 25.15 \\
\hline
\end{tabular}

$\mathrm{TP}=$ total publications, $\mathrm{TC}=$ total citations, $\mathrm{TC} / \mathrm{Y}=$ total citations per year, $\mathrm{TC} / \mathrm{P}=$ total citations per paper

Alexandre J. S. Morin has the most citations, with 994, followed by Ross D. Crosby (921) and Stephen A. Wonderlich (645). Alexandre J. S. Morin has the highest average number of citations per year, with 82.83 , followed by Ross D. Crosby (57.56) and Stephen A. Wonderlich (40.31). The highest values for the h-index corresponds to Ross D. Crosby (15), Michael G. Vaughn (12), and Alexandre J. S. Morin (10), Stephen A. Wonderlich (10), and James E. Mitchell (10). In terms of the average number of citations per document, Alexandre J. S. Morin has the most (49.7), followed by Ross D. Crosby (41.86) and James E. Mitchell (40.29). 


\subsubsection{Journals that have published research on LPA}

Papers on LPA have been published in 780 journals. Table 5 lists the most relevant journals in the field of LPA. The journal with the most publications and the most citations is Learning and Individual Differences, with 858 citations from its 47 publications. In the citation ranking, Learning and Individual Differences (858) is followed by Plos One (627) and the Journal of Youth and Adolescence (548). This same order applies for the average citations per year, with values of 71.50, 62.70, and 54.80, respectively. In the case of the h-index, Learning and Individual Differences (16) is followed by Personality and Individual Differences (12), and Plos One (11), the Journal of Youth and Adolescence (11), and the Journal of Affective Disorders (11). In the case of citations per paper, Learning and Individual Differences (18.26) is followed by the Journal of Youth and Adolescence (16.61) and Plos One (16.5).

\subsubsection{Most cited articles on LPA}

Next, analysis of the five most cited papers on LPA was conducted. Table 6 shows that the most cited paper on LPA, with 450 citations, is "Model selection and psychological theory: a discussion of the differences between the Akaike information criterion (AIC) and the Bayesian information criterion (BIC)" authored by Vrieze (2012) and published in Psychological Methods.

Next, Fig. 6 shows the list of authors who have published together and the citations of these works. The minimum number of documents to appear in this list was again chosen to be five articles. The figure shows a total of 125 authors forming 45 groups. Different groupings, shown in different colors, represent co-authorship.

Table 5 Most relevant journals by number of publications on LPA

\begin{tabular}{lccccc}
\hline Journal & TP & TC & TC/Y & h-index & TC/P \\
\hline Learning and Individual Differences & 47 & 858 & 71.50 & 16 & 18.26 \\
Frontiers in Psychology & 45 & 166 & 27.67 & 8 & 3.69 \\
Personality and Individual Differences & 41 & 486 & 48.60 & 12 & 11.85 \\
Plos One & 38 & 627 & 62.70 & 11 & 16.5 \\
Journal of Youth and Adolescence & 33 & 548 & 54.80 & 11 & 16.61 \\
Journal of Affective Disorders & 28 & 292 & 32.44 & 11 & 10.43 \\
International Journal of Environmental & 26 & 43 & 10.75 & 4 & 1.65 \\
$\quad$ Research and Public Health & & & & & \\
Journal of Child and Family Studies & 23 & 81 & 11.57 & 4 & 3.52 \\
Psychiatry Research & 23 & 287 & 26.09 & 10 & 12.48 \\
Addictive Behaviors & 21 & 252 & 21.00 & 10 & 12 \\
\hline
\end{tabular}

$\mathrm{TP}=$ total publications, $\mathrm{TC}=$ total citations, $\mathrm{TC} / \mathrm{Y}=$ total citations per year, $\mathrm{TC} / \mathrm{P}=$ total citations per paper 


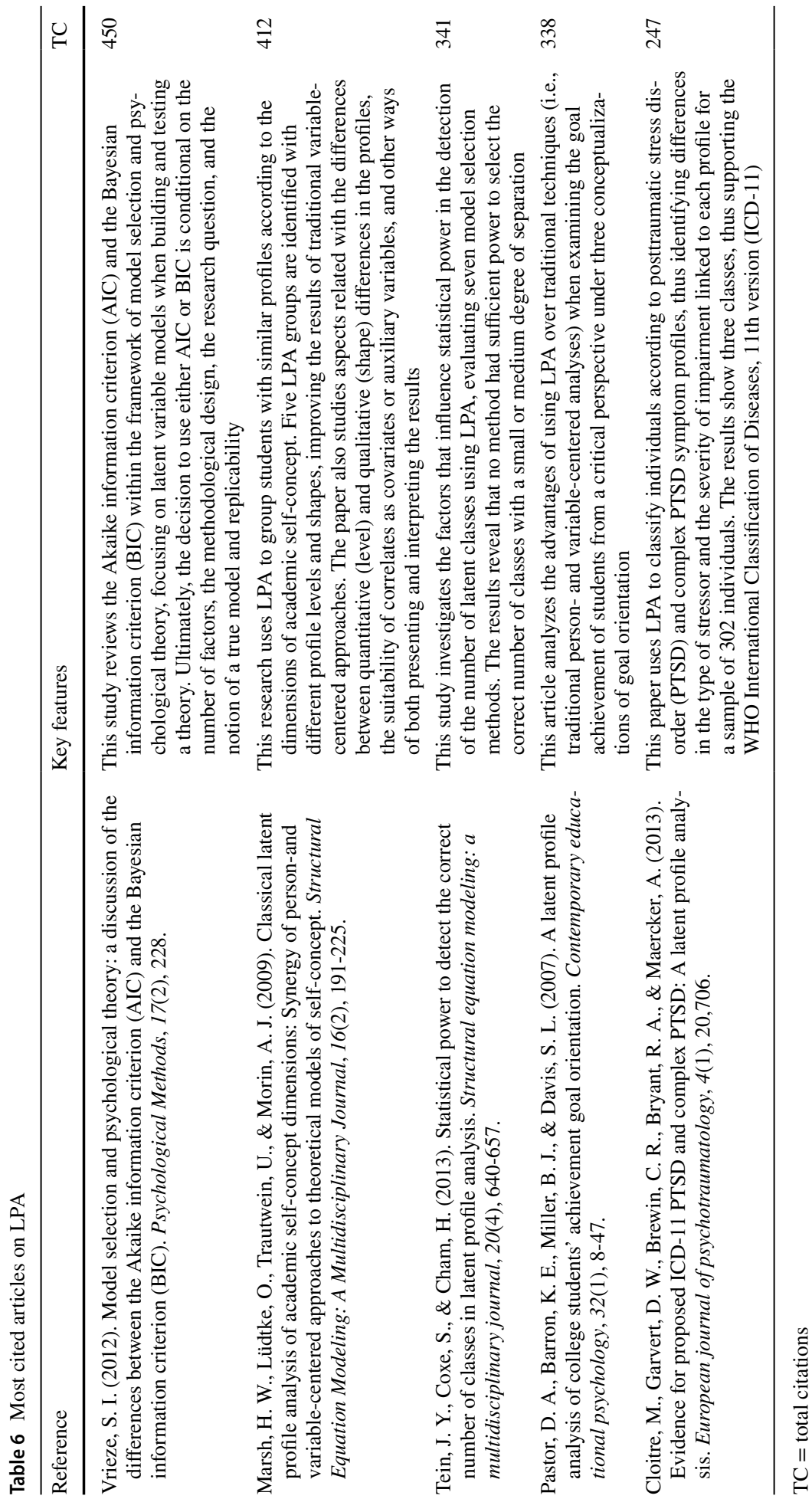




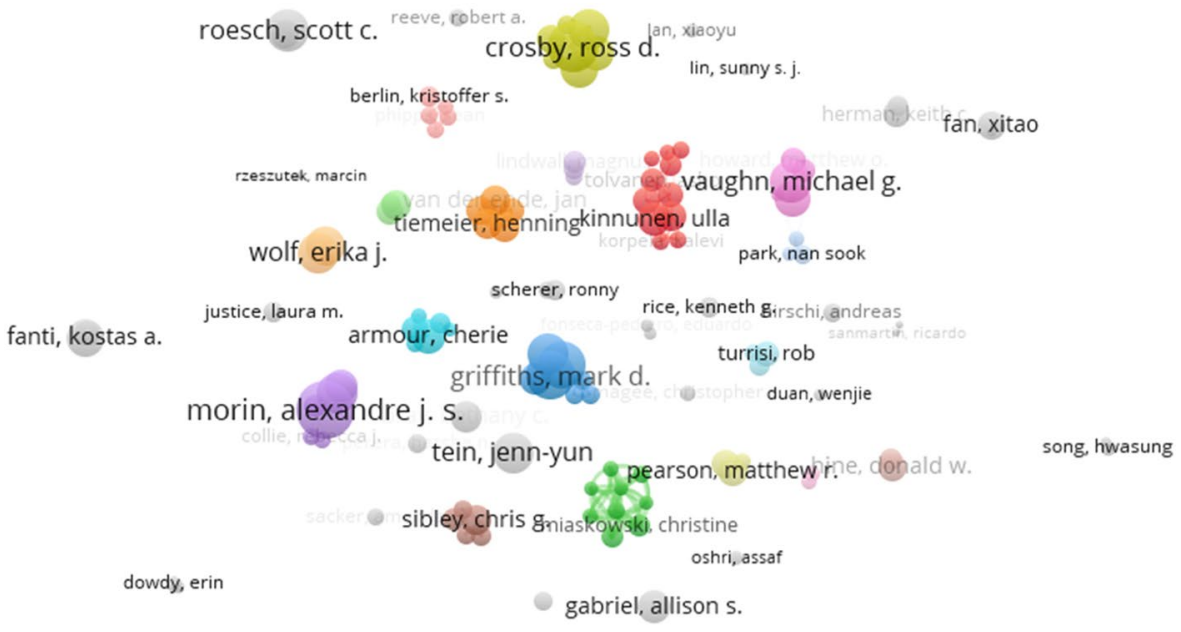

Fig. 6 Author linkages

\section{Conclusions}

This study offers a conceptual and bibliometric approach to the person-centered approaches of qualitative comparative analysis (QCA) and latent profile analysis (LPA). The main conclusions are now highlighted. Regarding the number of documents published, in both bibliometric analyses (QCA and LPA), the number of published documents was approximately 2000. In terms of the top 10 documents in the case of LPA, psychology is the subject area with the most publications. However, in the case of QCA, psychology is the area with the fewest. The first paper published on LPA dates back to 1959, and the first paper on QCA was published 18 years later. In 2021, more papers have been published on LPA than on QCA, although the difference is only 35. The Journal of Business Research has published the most papers on QCA, with 277 papers, whereas Learning and Individual Differences has published the most papers on LPA, with 48 papers. Finally, the most cited paper on QCA has 1000 more citations than the most cited paper on LPA. A limitation of this study is the use of Web of Science (WOS) as the sole data source. Other databases such as Scopus could also be used. Further research should continue to analyze the evolution of this field over time, especially if new person-centered approaches emerge.

Funding Open Access funding provided thanks to the CRUE-CSIC agreement with Springer Nature. Alicia Mas-Tur thanks the Generalitat Valenciana for funding under Project GV/2021/121 to support this research. Pau Sendra-Pons thanks the Spanish Ministry of Universities for funding under FPU2019/00867 to support this research.

\section{Declarations}

Conflict of interest The authors have no relevant financial or non-financial interests to disclose. 
Open Access This article is licensed under a Creative Commons Attribution 4.0 International License, which permits use, sharing, adaptation, distribution and reproduction in any medium or format, as long as you give appropriate credit to the original author(s) and the source, provide a link to the Creative Commons licence, and indicate if changes were made. The images or other third party material in this article are included in the article's Creative Commons licence, unless indicated otherwise in a credit line to the material. If material is not included in the article's Creative Commons licence and your intended use is not permitted by statutory regulation or exceeds the permitted use, you will need to obtain permission directly from the copyright holder. To view a copy of this licence, visit http://creativecommons.org/licenses/by/4.0/.

\section{References}

Allen, M., Aldred, M.L.: Varieties of capitalism, governance, and high-tech export performance: A fuzzy-set analysis of the new EU member states. Empl. Relat. 33(4), 334-355 (2011). https://doi. org/10.1108/01425451111140622

Baumgartner, M.: Qualitative Comparative Analysis and robust sufficiency. Quali. \& Quanti. (2021). https://doi.org/10.1007/s11135-021-01157-z

Bergman, L.R., Magnusson, D., El-Khouri, B.M.: Studying individual development in an interindividual context: A person-oriented approach. Vol. 4 of Paths through life (D. Magnusson, Series Ed.). Mahwah, NJ: Erlbaum. (2003)

Bergold, S., Wendt, H., Kasper, D., Steinmayr, R.: Academic competencies: Their interrelatedness and gender differences at their high end. Educ. Psychol-UK. 109(3), 439 (2017). https://doi.org/10. 1037/edu0000140

Cabrilo, S., Dahms, S.: How strategic knowledge management drives intellectual capital to superior innovation and market performance. J. Know. Manag. (2018)

Cancino, C., Merigó, J.M., Coronado, F., Dessouky, Y., Dessouky, M.: Forty years of Computers \& Industrial Engineering: A bibliometric analysis. Compt. \& Indus. Engin. 113, 614-629 (2017). https://doi.org/10.1016/j.cie.2017.08.033

Charles, S.L.: A latent profile analysis of suburban single-family rental housing (SFR) neighborhoods. Hous. Policy Deb. 30(2), 205-227 (2020). https://doi.org/10.1080/10511482.2019.1657927

Chen, C.X., Zhang, J., Gilal, F.G.: Composition of motivation profiles at work using latent analysis: theory and evidence. Psy. Res. and Beh. Manag. 12, 811 (2019). https://doi.org/10.2147/PRBM. S210830

Crawford, S.: What is the energy policy-planning network and who dominates it?: A network and QCA analysis of leading energy firms and organizations. Energ. Policy. 45, 430-439 (2012). https://doi. org/10.1016/j.enpol.2012.02.053

Fiss, P.C.: A set-theoretic approach to organizational configurations. Acad. Manag. Rev. 32, 1180-1198 (2007). https://doi.org/10.5465/amr.2007.26586092

Fiss, P.C.: Building better causal theories: A fuzzy set approach to typologies in organization research. Acad. of Manag. J. 54(2), 393-420 (2011). https://doi.org/10.5465/amj.2011.60263120

Forsythe, P.J.: Profiling customer perceived service quality expectations in made-to-order housing construction in Australia. Engin. Const. and Arch. Manag. (2012)

Gabriel, A.S., Campbell, J.T., Djurdjevic, E., Johnson, R.E., Rosen, C.C.: Fuzzy profiles: Comparing and contrasting latent profile analysis and fuzzy set qualitative comparative analysis for personcentered research. Organ. Res. Meth. 21(4), 877-904 (2018). https://doi.org/10.1177/1094428117 752466

Gong, Y., Li, J., Xie, J., Tan, Y.: Relationship between types of food choice motives and well-being among young and middle-aged Chinese adults. Int. J. of Consum. Stu. 44(4), 369-378 (2020). https://doi.org/ $10.1111 /$ ijcs. 12573

Greckhamer, T., Misangyi, V.F., Elms, H., Lacey, R.: Using qualitative comparative analysis in strategic management research: An examination of combinations of industry, corporate, and business-unit effects. Org. Res. Methods. 11(4), 695-726 (2008)

Griffin, L.J., Botsko, C.: Theoretical generality, case particularity: Qualitative comparative analysis of trade union growth and decline. Int. J. of Comp. Socio. 32(1), 110 (1991). https://doi.org/10.1163/97890 04477384_007

Grigoryev, D., van de Vijver, F.: Acculturation profiles of Russian-speaking immigrants in Belgium and their socio-economic adaptation. J. Multilin. and Multicul. Develop. 38(9), 797-814 (2017). https:// doi.org/10.1080/01434632.2016.1268145 
Haraldsen, H.M., Ivarsson, A., Solstad, B.E., Abrahamsen, F.E., Halvari, H.: Composites of perfectionism and inauthenticity in relation to controlled motivation, performance anxiety and exhaustion among elite junior performers. Europ. J. of Sport Sci. (2020). https://doi.org/10.1080/17461391.2020.1763478

Hillenbrand, C., Money, K.: Segmenting stakeholders in terms of corporate responsibility: Implications for reputation management: AMJ. Austr. Mark. J. 17(2), 99-105: (2009). Retrieved from https://search. proquest.com/scholarly-journals/segmenting-stakeholders-terms-corporate/docview/199341590/se-2? accountid $=14777$

Hine, D.W., Phillips, W.J., Cooksey, R., Reser, J.P., Nunn, P., Marks, A.D.,. ., Watt, S.E.: Preaching to different choirs: How to motivate dismissive, uncommitted, and alarmed audiences to adapt to climate change? Glob. Environ. Change. 36, 1-11 (2016). https://doi.org/10.1016/j.gloenvcha.2015.11.002

Hodis, F.A., Hodis, G.M.: Patterns of motivation and communication in learning environments: a latent profile analysis. Soc. Psy. Educ. 23(6), 1659-1685 (2020)

Horacek, T.M., Yildirim, E.D., Seidman, D., Byrd-Bredbenner, C., Colby, S., White, A.A.,. ., Kattelmann, K.: Redesign, field-testing, and validation of the physical activity campus environmental supports (PACES) audit. J. Environ. Pub. Health (2019). https://doi.org/10.1155/2019/5819752

Howard, M.C., Hoffman, M.E.: Variable-centered, person-centered, and person-specific approaches: where theory meets the method. Org. Res. Methods. 21(4), 846-876 (2018). https://doi.org/10. $1177 / 1094428117744021$

Kaptein, M. (ed.): Modern Statistical Methods for HCI. Human-Computer Interaction Series. Springer, Cham. https://doi.org/10.1007/978-3-319-26633-6_12

Katz, D., Kahn, R.L.: The social psychology of organizations, 2nd edn. Wiley, New York (1978)

Kokko, K., Feldt, T.: Longitudinal profiles of mental well-being as correlates of successful aging in middle age. Int. J. Beh. Develop. 42(5), 485-495 (2018). https://doi.org/10.1177/0165025417739177

Kori, K., Pedaste, M., Must, O.: The academic, social, and professional integration profiles of information technology students. ACM Trans. on Comp. Edu. (TOCE). 18(4), 1-19 (2018). https://doi.org/ $10.1145 / 3183343$

Kraus, S., Ribeiro-Soriano, D., Schüssler, M.: Fuzzy-set qualitative comparative analysis (fsQCA) in entrepreneurship and innovation research-the rise of a method. Int. Entrep. and Manag. J. 14(1), 15-33 (2018)

Laursen, B., Hoff, E.: Person-centered and variable-centered approaches to longitudinal data. MerrillPalmer Quart.: (1982-), 377-389. (2006)

Longest, K.C., Vaisey, S.: Fuzzy: A program for performing qualitative comparative analyses (QCA) in Stata. STATA J. 8, 79-104 (2008). https://doi.org/10.1177/1536867X0800800106

López-Rubio, P., Roig-Tierno, N., Mas-Tur, A.: Regional innovation system research trends: toward knowledge management and entrepreneurial ecosystems. Int. J. Quali. Inn. 6(1), 1-16 (2020)

Magnusson, D.: The person approach: Concepts, measurement models, and research strategy. In: Peck, S.C., Roeser, R.W. (eds.) New directions for Child and Adolescent development. Person-centered approaches to studying development in context (No. 101, pp. 3-23. Jossey-Bass, San Francisco (2003)

Mas-Tur, A., Modak, N.M., Merigó, J.M., Roig-Tierno, N., Geraci, M., Capecchi, V.: Half a century of Quality \& Quantity: a bibliometric review. Quali. \& Quanti. 53(2), 981-1020 (2019). https://doi. org/10.1007/s11135-018-0799-1

Mas-Tur, A., Roig-Tierno, N., Sarin, S., Haon, C., Sego, T., Belkhouja, M.,. ., Merigó, J.M.: Co-citation, bibliographic coupling and leading authors, institutions and countries in the 50 years of Technological Forecasting and Social Change. Techno. Fore. and Soc. Change. 165, 120487 (2021). https:// doi.org/10.1016/j.techfore.2020.120487

Merigó, J.M., Cancino, C.A., Coronado, F., Urbano, D.: Academic research in innovation: a country analysis. Scientometrics 108(2), 559-593 (2016)

Merigó, J.M., Mas-Tur, A., Roig-Tierno, N., Ribeiro-Soriano, D.: A bibliometric overview of the Journal of Business Research between 1973 and 2014. J. Bus. Res. 68(12), 2645-2653 (2015). https://doi. org/10.1016/j.jbusres.2015.04.006

Meyer, A.D., Tsui, A.S., Hinings, C.R.: Configurational approaches to organizational analysis. Aca. Manag. J. 36(6), 1175-1195 (1993). https://doi.org/10.5465/256809

Mill, J.: A system of logic, ratiocinative and inductive. London: Longmans, Green, Reader, and Dyer: (1843)

Mill, J.S.: A system of logic, ratiocinative and inductive: Being a connected view of the principles of evidence and the methods of scientific investigation. Harper (1884)

Morin, A.J., Morizot, J., Boudrias, J.S., Madore, I.: A multifoci person-centered perspective on workplace affective commitment: A latent profile/factor mixture analysis. Org. Res. Methods. 14(1), 58-90 (2011). https://doi.org/10.1177/1094428109356476 
Morosan, C., DeFranco, A.: Classification and characterization of US consumers based on their perceptions of risk of tablet use in international hotels. J. Hosp. Tour. Techn. (2019). https://doi.org/10. 1108/JHTT-07-2018-0049

Oberski, D.: Mixture Models: Latent Profile and Latent Class Analysis. In: Robertson J. (2016)

Park, S., Park, S.Y., Oh, G., Oh, I.H.: Latent Profiles Based on Light Physical Activity, Sedentary Behavior, Perceived Body Shape, and Body Mass Index in Patients with Dyslipidemia Influence Their Quality of Life. Int. J. Envir. Res. Public Health. 16(20), 4034 (2019). https://doi.org/10.3390/ijerph16204034

Ragin, C.: The comparative method. University of California Press, Berkeley (1987)

Ragin, C.: Fuzzy-set social science. University of Chicago Press, Chicago (2000)

Ragin, C.C.: Redesigning social inquiry: Fuzzy sets and beyond, pp. 190-212. University of Chicago Press, Chicago (2008)

Ragin, C.C.: Reflections on casing and case-oriented research, pp. 522-534. The Sage handbook of casebased methods (2009)

Rey-Martí, A., Ribeiro-Soriano, D., Palacios-Marqués, D.: A bibliometric analysis of social entrepreneurship. J. Bus. Res. 69(5), 1651-1655 (2016). https://doi.org/10.1016/j.jbusres.2015.10.033

Rivard, S., Lapointe, L.: Information technology implementers' responses to user resistance: Nature and effects. MIS Q. (2012). https://doi.org/10.2307/41703485

Roig-Tierno, N., Gonzalez-Cruz, T.F., Llopis-Martinez, J.: An overview of qualitative comparative analysis: A bibliometric analysis. J. Inno. \& Know. 2(1), 15-23 (2017). https://doi.org/10.1016/j.jik.2016.12. 002

Schneider, C.Q., Wagemann, C.: Set-theoretic methods for the social sciences: A guide to qualitative comparative analysis. Cambridge University Press (2012)

Sendra-Pons, P., Belarbi-Muñoz, S., Garzón, D., Mas-Tur, A.: Cross-country differences in drivers of female necessity entrepreneurship. Serv Bus 1-19 (2021)

Vassinen, A.: Configurational explanation of marketing outcomes. Aalto University School of Economics, Espoo (2012)

Vermunt, J.K., Magidson, J.: Local independence. Encyclop. Soc. Scien. Res. Methods, $732-733$ (2004)

Vink, M.P., Vliet, O.V.: Not quite crisp, not yet fuzzy? Assessing the potentials and pitfalls of multi-value QCA. Field Methods. 21(3), 265-289 (2009). https://doi.org/10.1177/1525822X09332633

Vis, B.: The comparative advantages of fsQCA and regression analysis for moderately large-N analyses. Sociol. Methods Res. 41(1), 168-198 (2012). https://doi.org/10.1177/0049124112442142

Wang, M., Hanges, P.J.: Latent class procedures: Applications to organizational research. Org. Res. Methods. 14(1), 24-31 (2011). https://doi.org/10.1177/1094428110383988

Williams, G.A., Kibowski, F.: Latent class analysis and latent profile analysis. Handbook of methodological approaches to community-based research: Qualitative, quantitative, and mixed methods 143-151: (2016)

Wilson: Holly Skodol Limiting Intrusion-Social Control of Outsiders in a Healing Community. Nursing Research: March 1977 26(2), 103-111 (1977)

Woodside, A.G.: Moving beyond multiple regression analysis to algorithms: Calling for adoption of a paradigm shift from symmetric to asymmetric thinking in data analysis and crafting theory. J. Bus. Res. 66(4), 463-472 (2013). https://doi.org/10.1016/j.jbusres.2012.12.021

Wu, P.-L., Yeh, S.-S., Huan, T.-C., Woodside, A.G.: Applying complexity theory to deepen service dominant logic: Configural analysis of customer experience-and-outcome assessments of professional services for personal transformations. J. Bus. Res. (2014). https://doi.org/10.1016/j.jbusres.2014.03.012

Yong, K., Mannucci, P.V., Lander, M.W.: Fostering creativity across countries: The moderating effect of cultural bundles on creativity. Org. Beh. Hum. Deci. Proc. 157, 1-45 (2020). https://doi.org/10.1016/j. obhdp.2019.12.004

Publisher's Note Springer Nature remains neutral with regard to jurisdictional claims in published maps and institutional affiliations. 